\title{
HIGH, USUAL AND IMPAIRED FUNCTIONING IN COMMUNITY-DWELLING OLDER MEN AND WOMEN: FINDINGS FROM THE MACARTHUR FOUNDATION RESEARCH NETWORK ON SUCCESSFUL AGING
}

\author{
Lisa F. Berkman, ${ }^{1}$ Teresa E. Seeman, ${ }^{1}$ Marilyn Albert, ${ }^{2}$ Dan Blazer, ${ }^{3}$ \\ Robert Kahn, ${ }^{4}$ Richard Mohs, ${ }^{5}$ Caleb Finch, ${ }^{6}$ Edward Schneider, ${ }^{6}$ \\ Carl Cotman, ${ }^{7}$ Gerald McClearn, ${ }^{8}$ John Nesselroade, ${ }^{9}$ \\ David Featherman, ${ }^{10}$ Norman Garmezy, ${ }^{11}$ Guy McK hanN, ${ }^{12}$ Gilbert Brim, ${ }^{13}$ \\ DENIS PRAGER ${ }^{14}$ and JOHN ROWE ${ }^{15}$ \\ 'Yale University, Department of Epidemiology and Public Health, New Haven, CT 06510, \\ ${ }^{2}$ Massachusetts General Hospital, Departments of Psychiatry and Neurology, Boston, MA, ${ }^{3}$ Duke \\ University Medical Center, Department of Psychiatry, Durham, NC 27706, "University of \\ Michigan, Survey Research Center, Ann Arbor, MI 48109, 'Mount Sinai School of Medicine, \\ Veterans Administration Medical Center, Bronx, NY, 'University of Southern California, The \\ Andrus Gerontology Center, Los Angeles, CA 90089, ${ }^{7}$ University of California, Irvine, Department \\ of Psychobiology, Irvine, CA 92717, '8ennsylvania State University, Program in Biobehavioral \\ Health, University Park, PA 16802, 'University of Virginia, Department of Psychology, Charlot- \\ tesville, VA 22903, "'Social Science Research Council, New York, NY, "University of Minnesota, \\ Department of Psychology, Minneapolis, MN 55455, ${ }^{12} \mathrm{Johns}$ Hopkins University, The Mind/Brain \\ Institute, Baltimore, MD 21218, ${ }^{13}$ MacArthur Foundation Research Network on Successful \\ Mid-Life Development, Vero Beach, FL, ${ }^{14} \mathrm{John}$ D. and Catherine T. MacArthur Foundation, \\ Chicago, IL and ${ }^{15}$ Mount Sinai Medical Center, New York, NY, U.S.A.
}

(Received in revised form 11 May 1993)

\begin{abstract}
The objective of this study is to determine the range of complex physical and cognitive abilities of older men and women functioning at high, medium and impaired ranges and to determine the psychosocial and physiological conditions that discriminate those in the high functioning group from those functioning at middle or impaired ranges. The subjects for this study were drawn from men and women aged 70-79 from 3 Established Populations for the Epidemiologic Study of the Elderly (EPESE) programs in East Boston MA, New Haven CT, and Durham County NC screened on the basis of criteria of physical and cognitive function. In 1988, 4030 men and women were screened as part of their annual EPESE interview. 1192 men and women met criteria for "high functioning". Age and sex-matched subjects were selected to represent the medium $(n=80)$ and low $(n=82)$ functioning groups. Physical and cognitive functioning was assessed from performance-based examinations and self-reported abilities. Physical function measures focused on balance, gait, and upper body strength. Cognitive exams assessed memory, language, abstraction, and praxis. Significant differences for every performance-based examination of physical and cognitive function were observed across functioning groups. Low functioning subjects were almost 3 times as likely to have an income of $\$ \$ 5000$ compared to the high functioning group. They were less likely to have completed high school. High functioning subjects smoked cigarettes less and exercised more than others. They had higher levels of DHEA-S and peak expiratory flow rate. High functioning elders were more likely to engage in volunteer activities and score higher on scales of self-efficacy, mastery and report fewer psychiatric symptoms.
\end{abstract}

Successful aging Physical functioning Cognitive functioning 


\section{INTRODUCTION}

Studies of aging have traditionally focused on declines in functioning and increases in risk of disease and impairment with advancing aging. Age-associated losses in physical and cognitive abilities are commonly interpreted as normal and inevitable consequences of aging. Furthermore, standard assessments and methodological approaches often focus on functioning in the severely impaired range and on mean or average changes across age-groups. Such approaches obscure the vast and important heterogeneity and range in function observed among communitybased populations. Thus, we know little about the prevalence of such high levels of functioning among the older men and women nor have we made much progress in the identification of factors that determine rates of functional change or maintenance of abilities well into old age.

In an attempt to gain a better understanding of those factors that will promote the maintenance of vitality and resilience into late life, The MacArthur Foundation Research Network on Successful Aging initiated a multidisciplinary, longitudinal study of relatively healthy, wellfunctioning community-dwelling older Americans. The central theme of this work is that there is a distinction between usual and successful aging [1]. Usual aging, while average or normal in the statistical sense, is not without risk for specific diseases and adverse health outcomes. Concepts of successful aging tend to lead investigators toward a richer understanding of the full range of functioning observed in heterogeneous populations and a more solid understanding of the role extrinsic factors play in influencing variability of function within age groups [2].

Our aim was to identify a population-based cohort of high functioning older men and women and to compare their ranges of abilities and biomedical and psychosocial characteristics to those of older men and women who are functioning either in the "average" or mid-range, or who are doing poorly and have significant impairments and limitations. In addition to cross-sectional comparisons which are reported here, we plan a longitudinal follow-up of the high functioning cohort, to identify biomedical and psychosocial conditions that may not only protect against serious declines, but also promote resilience and vitality in elderly men and women who maintain abilities.

This multi-site study examines, in three population-based cohorts of men and women in their seventies, the range of functional abilities of relatively high functioning subjects and compares them to age- and sex-matched subjects who are functioning in middle and lower ranges. High functioning is operationalized for the purposes of this study as performance in the top tertile on a series of brief screening instruments assessing both physical and cognitive functioning. In addition to describing physical and cognitive functioning, we assess biomedical conditions, physiologic indicators of neuroendocrine, cardiovascular, hormonal, renal, metabolic, and pulmonary function, and psychological and social characteristics.

\section{METHODS}

\section{Subject selection}

Subjects were selected from three larger, population-based samples of individuals aged 65 and older in Durham, NC; East Boston, MA; and New Haven, CT; who are part of the NIA-funded "Established Populations for Epidemiologic Studies of the Elderly" (EPESE) [3]. When screened for the present study, during the 1988 EPESE annual interview, each of the EPESE cohorts had been followed for between 3 (Durham) and 6 years (East Boston and New Haven). Response rates to these EPESE interviews were uniformly high (over $90 \%$ ). The agerange for eligibility in the MacArthur Study was restricted to 70-79 to minimize the effects of age in subsequent analyses. Thus, EPESE age-eligible subjects were screened on the basis of six criteria of physical and cognitive function resulting in a pool of $\mathbf{4 0 3 0}$ screened subjects.

The screening criteria for high functioning identify, among those men and women 70-79, those in the upper tertile of both cognitive and physical functioning. The screening criteria were developed $a$ priori based on preliminary analyses from several cohort studies. The criteria are:

\section{Cognitive Performance:}

1. scores of 6 or more correct on the 9-item Short Portable Mental Status Questionnaire (SPMSO) developed by Pfieffer [4].

2. remembers 3 or more of 6 elements on a delayed recall of a short story.

\section{Physical Performance and Disability:}

1. reports no disability on a 7-item scale of activities of daily living (ADL) developed by Katz [5]. 
2. reports not more than one disability on 8 items tapping gross mobility and physical performance (e.g. walks $1 / 2$ mile, climb stairs, push heavy objects, lift groceries) developed by Nagi [6] and Rosow-Breslau [7].

3. able to hold a semi-tandem balance for at least 10 seconds, and

4. able to stand from a seated position 5 times within 20 seconds.

The criteria for the "medium" and "low" functioning groups were defined to divide the remainder of the 70-79 year olds into two equal sized groups. Screening criteria for the imtpaired (low functioning) group were:

\section{SPMSQ score of less than 6 correct} or

2. Physical disability of at least one ADL limitation or 2 or more disabilities in gross mobility or 3 or more disabilities in physical performance based on the scale developed by Nagi [6].

Subjects were eligible for inclusion in the low functioning group if they met any one of these criteria. The medium function group was defined as those who did not qualify in either the top or bottom tertiles of functioning. In effect, subjects were classified on the basis of their poorest performance in any single area. Thus, some subjects in the lower two functioning groups have high scores on cognitive performance but are unable to perform in physical domains (or vice versa).

Using these screening criteria, a cohort of 1313 subjects met criteria for the highest functional status group. Among these, $90.8 \%(n=1192)$ consented to be enrolled in the present study.

Among those who were age-eligible but did not meet these criteria $(n=2717)$, we also selected small random subsamples of subjects who were functioning in the middle tertile ("medium functioning") $(n=80)$ and subjects who had major impairments in either physical and/or cognitive functioning ("low functioning") $(n=82)$. Subjects for these latter two subsamples were selected in order to match their age and sex distributions to that of the high functioning group.

\section{MEASURES}

The cohort for this study was well characterized on previous EPESE interviews regarding sociodemographic conditions, behavioral risk factors such as cigarette smoking and alcohol consumption, chronic conditions and symptoms, and physical and mental health and functioning [3]. Accordingly the MacArthur Battery is focused on detailed assessments of functioning and capacity in the upper ranges and psychosocial and biomedical conditions hypothesized to be related to such functional abilities. Each of the subjects was asked to complete the MacArthur Battery, a 90 minute face-to-face interview designed to be given in the respondent's home and covering detailed assessments of physical and cognitive functioning and performance, productive activities, social networks and social support and other psychosocial characteristics and biomedical and health status measurements. As part of this battery, subjects were also asked to provide a blood sample and a 12-hour overnight urine sample. Among those who responded to the survey, $80.3 \%$ agreed to have blood drawn and $85.8 \%$ consented to urine collections.

\section{Physical and cognitive functional measures: performance and self-reports}

The portion of the MacArthur Battery assessing cognition was designed to assess intensively those aspects of higher cortical function that are necessary to perform complex cognitive activities, namely memory, language, abstraction, and praxis. The tests for each cognitive domain were selected from among previously developed, well standardized and reliable tests with the intention of including tests with a range of difficulty. We particularly aimed to include tests difficult enough so that even mild impairments could be detected and so that some errors would be made by older men and women who are not clinically demented.

Cognitive performance was assessed with 5 tasks that took approximately 15 minutes to administer. The first task, The Boston Naming Test, evaluates confrontation naming, a test of language [8]. Subjects are shown 18 drawings of concrete objects and are asked to name each object, ranging from common items to more uncommon items. A maximum of 10 seconds is allowed for response to each picture. Only items named that match identically with those listed are scored correctly so that no interviewer judgments are involved in scoring. The Boston Naming Test is part of the Consortium to Establish a Registry for Alzheimer's Disease (CERAD) Battery $[9,10]$. Test-retest reliability is excellent. Among controls in the CERAD study (i.e. non-demented elderly subjects) mean scores were the same over the one month 
test-retest period (14.6 vs 14.7). A second task was a delayed verbal memory test based on incidental recall of naming items from the Boston Naming Test. Incidental delayed recall requires recall of information to which the subject has been exposed but has not been explicitly instructed to remember and is one of the most difficult types of memory tests.

The third task evaluated spatial memory by means of the delayed recognition Span Test scored $0-17$. For this test, circular disks are placed one at a time on a board in specific order. As each new disk is added, the surface of the board is hidden from view and the subject is asked to name the new disk that has been added. The task differentiates normal controls from subjects with a range of neurological diseases [11]. Among the strengths of the test include its focus on spatial memory (distinct from verbal or language related abilities), ease in administration and lack of reliance on interviewers to make any judgments since scores are simply related to number of disks recalled.

The fourth test utilized items from the Similarities subtest of the Wechsler Adult Intelligence Scale--Revised (WAIS-R). It evaluates the ability of subjects to form abstract concepts, and is scored 0-16. Subjects are asked to explain how two different concrete objects are similar to one another, such as an orange and banana [12].

The final cognitive task was the copying of geometric figures adapted from an instrument developed by Rosen et al. [13] for use as part of a rating scale of Alzheimer's disease. Subjects were asked to copy a series of geometric figures including a diamond, a diamond in a square, and a 3-D cube. Figures were scored by a single trained rater according to a standardized scoring system. The test evaluates the subject's ability to perceive and reproduce spatial relationships.

Summary measures were developed for (1) total cognitive scores, which is the sum of all subtest scores and had a range of 0-89 and (2) memory scales, which is the sum of the delayed recall from the Boston Naming Test and the delayed recognition Span Test (range 0-35).

Physical performance measures were based on both lower body function (balance and gait), and upper body function (strength and dexterity). Many performance measures were judged on the basis of time taken to complete tasks. Timing is highly correlated with more clinical assessments of performance and is more easily standardized across interviewers [14]. In addition, timed tasks array responses of subjects along a very wide range and reveal the ability to accomplish tasks both well and quickly. Balance was assessed by a graded series of tests developed by Nevitt [15], which include the number of seconds (up to 10) a subject could hold a tandem stand with their eyes open. If they could complete that task, they were asked to do a tandem stand with their eyes closed. Subjects then completed a tandem walk and were assessed for number of steps taken (up to 10) and time to complete steps. Finally, subjects were timed, (up to 30 seconds) for a single leg stand.

Gait measures were based on assessments of a 10 foot walk. Subjects were asked to walk 10 feet at a normal pace, turn and return. They were then asked to complete the same walk at a fast pace. Measures are based on time to complete walks (in seconds) and assessments of step continuity and ability to make pivot turns. Respondents were also timed as they tapped a foot, switching back and forth between 2 " circles 1 foot apart while in a seated position. Measures include numbers of taps (up to 10) and time taken to complete taps.

Upper body function was assessed first by a measure of hand grip strength using a dynamometer. Measures were of maximum kilograms pressed using the dominant arm in three tries. Secondly, based on assessments developed by Williams [16], subjects were asked to sign their names. This hand signature was timed.

Self-reported physical activity was assessed using questions adapted from the Yale Physical Activity Survey (YPAS) [17] focusing on current leisure- and work-related activity. Physical activity questions assessed frequency of selected activities. Further, categories of intensity (light, moderate, strenuous) were defined based on intensity codes ( $\mathrm{kcal} / \mathrm{min}$ ) determined by Paffenbarger et al. [18] or Taylor et al. [19]. Summary scales were derived by multiplying the frequency of activity by the intensity code and then summing over all activities within the particular category of intensity. Data are presented for a summary index of strenuous and moderate physical activity.

Psychosocial assessments and productive activities

A major focus of the MacArthur Battery was on the social networks and support, and productive activities of subjects. Measures of productive activities were adapted from University 
of Michigan's Survey of "Americans Changing Lives" [20]. The instrument taps degree of participation in volunteer activities, child care, paid employment and other forms of productive activity. Measures of social networks and support were drawn from EPESE surveys, and work at Yale, University of Michigan and Duke [21-23]. Scales measure structural characteristics of network: size, geographical proximity, and frequency of contact. Support measures focus on the quality of emotional and instrumental support and perceptions of adequacy as well as demands and conflicts. In a test-retest of 22 elderly subjects assessed 4 weeks apart, Spearman correlation coefficients ranged from $0.54(p<0.01)$ for measures assessing network size to $0.51(p<0.05)$ for instrumental support, to $0.41(p<0.10)$ for negative aspects of ties to $0.23(p>0.10)$ for emotional support. Since these questions are highly structured, we interpret such test-retest correlations as a test of temporal stability of responses more than a test of inter-rater reliability.

Other psychosocial measures include subscales from the Hopkins' Symptom Checklist on depression, anxiety, interpersonal problems and somatization [24,25], a 7-item scale of personal mastery developed by Pearlin et al. [26] and a scale of self-efficacy developed by Rodin [27]. Brief measures of life satisfaction [28], happiness, and demands and latitudes in daily life [29] are included.

\section{Biomedical assessments}

Measurement of seated and postural blood pressure, pulmonary function and waist/hip ratio were part of the biomedical protocol. The Hypertension Detection and Follow-up Program protocol was used to obtain seated blood pressure readings [30]. Systolic and diastolic pressures were calculated as the average of three readings. Waist/hip ratio was assessed based on procedures developed by Lohman et al. [31]: we measured waist at its narrowest point befween the ribs and iliac crest, and the hips at the iliac crest. A second hip circumference was also taken at the maximal buttocks level. Pulmonary function was assessed by the peak flow rate of subjects using a mini-Wright meter. Subjects were asked to exhale at maximal effort through the meter. Measures are based on the average of three attempts [32].

Measures of self-reports of 8 chronic conditions and symptoms of angina pectoris based on standard assessments developed by Rose [33] as well as medications are drawn from recent EPESE interviews.

\section{Physiological measures from blood and urine specimens}

A unique feature of the MacArthur Battery is the information available from urine and blood collections. The development of standardized urine collection procedures for almost 1200 elderly across 3 geographic sites represented a major effort. Pilot tests indicated that 12 hour specimens from 8:00 p.m.-8:00 a.m. and 24 hour specimens were highly correlated. Spearman correlation coefficients for 12 and 24 urine samples for 10 subjects were 0.95 for epinephrine, 0.80 for norepinephrine and 0.81 for cortisol. Twelve hour samples were used in this study since they were easier to obtain and were more acceptable to subjects. We developed insulated cooler packs that respondents could keep at home which would permit optimal urine temperature to be maintained to preserve the specimens. A bottle within each cooler pack contained $12 \mathrm{ml}$ of $6 \mathrm{~N} \mathrm{HCl}$ to acidify and preserve the urine during collection. Respondents were instructed to begin urine collection procedures at 8:00 p.m. and to continue until 8:00 a.m. the following morning. Laboratory personnel went to the respondents' house that morning to collect specimens. Upon collection, the mean temperature of the specimens was $14.6^{\circ} \mathrm{C}$ with a $\mathrm{pH}$ of $2-3$. A $60 \mathrm{ml}$ aliquot of urine was then sent to Nichols Laboratories for assays of cortisol, epinephrine, norepinephrine, dopamine and creatinine content. All results are adjusted to creatinine levels to reflect grams/ gram creatinine. Urinary free cortisol was assayed by high performance liquid chromatography (HPLC) $[34,35]$. Urine catecholamines were extracted via column chromatography and also determined by HPLC [36].

A phlebotomist was sent to each respondent's home to draw blood. Although subjects were not required to be fasted, most blood samples were taken early in the morning before subjects had eaten. Samples were processed and frozen within 8 hours of blood drawing. $9 \mathrm{~cm}^{3}$ of blood were drawn in serum-separator tubes. Blood was allowed to clot and the tube was centrifuged at 1500 RCF for 10 minutes in a refrigerated $\left(4^{\circ} \mathrm{C}\right)$ centrifuge. The sera were then sent to Nichols Laboratories for measurements of HDL and total cholesterol, dehydroepiandrosterone sulfate (DHEAS) and serum glutamic oxalacetic transaminase (SGOT). Another 
$10 \mathrm{~cm}^{3}$ of blood was drawn into heparinized tubes, two of which were removed after mixing for assays of glycosylated hemoglobin ( $\mathrm{HbA})$. This measure provides an assessment of integrated long-term blood glucose concentrations and was assayed using affinity chromatography methods [37]. The remainder was centrifuged and the plasma and cell pellet were frozen for future analyses.

\section{Analysis}

Statistical analyses are based on comparisons across the high functioning cohort and age- and sex-matched controls who represent groups with medium and low functional ability. Mean differences or percentages across groups are used for comparisons. The SAS software package general linear models (GLM) was used to obtain means, standard deviations and tests of significance for continuous variables [38]. Tests of significance for differences in percentages are based on chi-square.

\section{RESULTS}

When EPESE respondents who met age-eligibility criteria (ages 70-79) were screened for physical and cognitive functioning, 32.6\% met criteria. Those who passed the screen for high functioning were more likely to be in their early seventies and more likely to be male than respondents who did not meet criteria.

The eligible subjects who consented to be part of the study form the high functioning cohort $(n=1192)$. Smaller samples of subjects were randomly selected from among the ineligible EPESE subjects 70-79 years old who were functioning at medium and low levels. Table 1 shows the final number of respondents in the three functioning groups and their age and sex distribution. Among those in the highest functioning group, the mean age is 75.3 and $44.5 \%$ are male. The two other groups selected to be age and sex-matched to the highest functioning group show similar distributions. Their mean ages and the percentage male are not significantly different from the high functioning group. Thus,

Table 1. Age and sex distribution among high, medium and low age- and sex-matched function-

\begin{tabular}{lccc}
\multicolumn{4}{c}{ ing groups } \\
\hline Characteristic & $\begin{array}{c}\text { High } \\
(n=1192)\end{array}$ & $\begin{array}{c}\text { Medium } \\
(n=80)\end{array}$ & $\begin{array}{c}\text { Low } \\
(n=82)\end{array}$ \\
\hline Age (mean yr) & 75.3 & 76.1 & 76.2 \\
$\%$ Male & 44.5 & 43.8 & 46.3 \\
\hline
\end{tabular}

differences in characteristics among groups will not be attributable to age or gender differences.

Comparisons among the three groups on more sensitive performance-based assessments of physical and cognitive function can be seen as a validation of our cruder screening measures (Tables 2-4) and provide construct validation of the assessment tools. Table 2 shows that the respondents in the high functioning group perform significantly better on virtually every measure of physical function, ranging from lower body assessments of balance and gait to upper body measures of strength (hand grip) and coordination (signature time) $(p \leqslant 0.05)$. In these analyses, subjects unable to perform specific tests are given values of zero. In analyses not shown, when such subjects were excluded from analysis, trends were similar. With only one exception, there is a clear gradient in performance, with those in the high group performing better than those in the medium functioning group and those in the medium group doing better than those with impairments. It should be noted that in some cases the standard deviations accompanying these measures are quite large, reflecting additional variability in function within groups.

Table 3 shows means and standard deviations for performance scores for tests of cognitive function across the three groups. Again, those in the high functioning group performed significantly better on all cognitive tests, ranging from those tapping memory and delayed recall to those assessing visuo-spatial abilities and abstract reasoning (similarities) $(p \leqslant 0.001)$. Differences in cognitive scores between the medium functioning and low (impaired) group are not as great as observed differences in physical ability. These smaller differences are likely to be the result of the greater prevalence of physical rather than cognitive impairment among those in the most impaired group.

The relationships of sociodemographic characteristics, health-related behaviors, biomedical conditions and psychosocial factors across the three functioning groups are displayed in Tables 4-6. Since these conditions were not part of the screening assessment, they serve to inform us about how function is associated with these other characteristics. Table 4 shows the relationship of functional status to social class, health-related behaviors and number of self-reported chronic conditions and selfrated health. Income, education and race are all differentially distributed across the high, 
Table 2. Physical performance measures in high, medium and low functioning groups

\begin{tabular}{|c|c|c|c|c|c|c|c|c|c|}
\hline \multirow{2}{*}{$\begin{array}{l}\text { Performance } \\
\text { measures }\end{array}$} & \multicolumn{3}{|c|}{ High } & \multicolumn{3}{|c|}{ Medium } & \multicolumn{3}{|c|}{ Low } \\
\hline & 8 & SD & $n$ & $x$ & SD & $n$ & $\bar{X}$ & SD & $n$ \\
\hline \multicolumn{10}{|l|}{ Lower body } \\
\hline Balance & & & & & & & & & \\
\hline $\begin{array}{l}\text { Tandem stand } \text { d }^{* * *} \\
\text { (eyes open) sec }\end{array}$ & 8.0 & 3.2 & 1190 & 6.1 & 4.3 & 78 & 3.6 & 4.3 & 82 \\
\hline $\begin{array}{l}\text { Tandem stand* } \\
\text { (eyes closed) sec }\end{array}$ & 4.2 & 3.4 & 801 & 3.0 & 2.6 & 39 & 3.6 & 2.7 & 19 \\
\hline $\begin{array}{l}\text { Tandem walk*** } \\
\text { No. steps }\end{array}$ & 7.4 & 3.4 & 796 & 5.9 & 3.8 & 36 & 5.0 & 3.9 & 20 \\
\hline $\begin{array}{l}\text { Single leg } \\
\text { stand*** }\end{array}$ & 7.0 & 3.4 & 1190 & 5.7 & 3.7 & 68 & 5.0 & 3.7 & 47 \\
\hline \multicolumn{10}{|l|}{ Gait } \\
\hline \multicolumn{10}{|l|}{ Time to complete } \\
\hline Normal $^{* * *}$ & 10.0 & 4.6 & 1189 & 13.7 & 9.4 & 77 & 23.5 & 17.7 & 79 \\
\hline Fast*** & 7.1 & 3.2 & 1182 & 11.3 & 10.3 & 77 & 19.0 & 15.8 & 79 \\
\hline $\begin{array}{l}\text { Step cont } \\
\text { (\% yes) }{ }^{* * *}\end{array}$ & 45.9 & - & 1180 & 90.7 & - & 75 & 84.1 & - & 63 \\
\hline $\begin{array}{l}\text { Pivot } \\
(\% \text { yes) }\end{array}$ & 48.1 & - & 1180 & 36.0 & - & 75 & 28.6 & 一 & 63 \\
\hline Foot tapping*** & 0.5 & 0.2 & 1187 & 1.0 & 3.3 & 78 & 3.6 & 7.9 & 77 \\
\hline \multicolumn{10}{|l|}{ Upper body } \\
\hline $\begin{array}{l}\text { Hand grip } \\
(\max \mathrm{kg})\end{array}$ & 29.5 & 10.9 & 1187 & 27.4 & 9.5 & 80 & 24.8 & 10.5 & 82 \\
\hline Signature**** & 10.2 & 3.9 & 1187 & 11.8 & 4.9 & 80 & 12.8 & 6.0 & 78 \\
\hline
\end{tabular}

medium and impaired functioning groups $(p \leqslant 0.001)$. Indeed the differences between groups are quite dramatic. Elderly subjects in the low (impaired) group are almost three times more likely to have an annual income of under $\$ 5000$ than those in the highest functioning group. They are less likely to have completed high school and are more likely to be non-white. Cigarette smoking and participation in strenuous physical activities are also associated with differences in functional status $(p \leqslant 0.05)$. These associations must be interpreted cautiously since they are cross-sectional. Those in the highest functioning group are also more likely to consume alcohol than others. This potentially protective effect of alcohol may reflect a survival bias with those in the impaired group who drank underrepresented due to excessive mortality and non-participation. Finally, those in the high functioning group have better selfassessed health and significantly fewer chronic conditions $(p \leqslant 0.001)$.

Table 5 presents comparative data on physiologic parameters, including results of blood and urine assays, tests of pulmonary function and blood pressure. Two findings are particularly

Table 3. Differences in cognitive performance in high, medium, and low functioning groups

\begin{tabular}{|c|c|c|c|c|c|c|c|c|c|}
\hline \multirow[b]{2}{*}{ Cognitive measure } & \multicolumn{3}{|c|}{ High } & \multicolumn{3}{|c|}{ Medium } & \multicolumn{3}{|c|}{ Low } \\
\hline & $\bar{X}$ & SD & $n$ & 8 & SD & $n$ & $\bar{X}$ & SD & $n$ \\
\hline $\begin{array}{l}\text { Naming*** } \\
(0-18)\end{array}$ & 16.6 & 1.8 & 1190 & 15.8 & 2.0 & 77 & 15.2 & 3.4 & 82 \\
\hline $\begin{array}{l}\text { Abstraction *** } \\
\quad(0-16)\end{array}$ & 6.6 & 4.7 & 1189 & 4.6 & 9.2 & 80 & 4.1 & 4.3 & 82 \\
\hline $\begin{array}{l}\text { Copying*** } \\
\quad(0-20)\end{array}$ & 14.9 & 3.2 & 1186 & 13.2 & 3.4 & 78 & 12.4 & 4.5 & 81 \\
\hline $\begin{array}{l}\text { Delayed recall }{ }^{* * *} \\
\quad(0-18)\end{array}$ & 5.5 & 2.3 & 1185 & 3.8 & 2.3 & 77 & 4.0 & 2.5 & 80 \\
\hline $\begin{array}{l}\text { Delayed recog.*** } \\
(0-18)\end{array}$ & 9.2 & 3.5 & 1190 & 7.9 & 2.9 & 78 & 7.4 & 3.5 & 82 \\
\hline $\begin{array}{l}\text { Total memory*** } \\
\qquad(0-35)\end{array}$ & 14.7 & 4.5 & 1190 & 11.7 & 4.3 & 78 & 11.3 & 4.9 & 82 \\
\hline $\begin{array}{l}\text { Total cognitive**** } \\
(0-89)\end{array}$ & 53.0 & 9.9 & 1175 & 45.9 & 9.9 & 76 & 44.3 & 11.5 & 78 \\
\hline
\end{tabular}


Table 4. Social and behavioral factors in high, medium and low functioning groups

\begin{tabular}{|c|c|c|c|c|c|c|c|c|c|}
\hline \multirow[b]{2}{*}{ Condition } & \multicolumn{3}{|c|}{ High } & \multicolumn{3}{|c|}{ Medium } & \multicolumn{3}{|c|}{ Low } \\
\hline & $\bar{X} / \%$ & SD & $n$ & $\bar{X} / \%$ & SD & $n$ & $\bar{X} / \%$ & SD & $n$ \\
\hline $\begin{array}{l}\text { Cigarette smoking* } \\
\text { (pack/yr) }\end{array}$ & 20 & 32 & 1037 & 24 & 38 & 76 & 30 & 40 & 77 \\
\hline $\begin{array}{l}\text { Alcohol consumption } \\
\text { ( } \% \text { drink any) })^{* *}\end{array}$ & 42.5 & - & 1089 & 32.9 & - & 76 & 26.0 & - & 77 \\
\hline $\begin{array}{l}\text { Physical activity } \\
\text { Strenuous (hr/yr) }\end{array}$ & 116 & 127 & 1031 & 52.3 & 65.5 & 76 & 44.8 & 74.6 & 76 \\
\hline $\begin{array}{l}\text { Income*** } \\
\qquad(\% \leqslant 5000)\end{array}$ & 11.5 & - & 945 & 19.1 & - & 68 & 29.2 & - & 65 \\
\hline $\begin{array}{l}\text { Education } * * * \\
(\% \leqslant 12)\end{array}$ & 78.1 & - & 1036 & 86.8 & - & 76 & 90.9 & - & 77 \\
\hline $\begin{array}{l}\text { Race**** } \\
\quad(\% \text { White })\end{array}$ & 78.0 & - & 1036 & 66.7 & - & 75 & 62.3 & - & 77 \\
\hline $\begin{array}{l}\text { Self-rated health }{ }^{* * *} \\
\text { (\% excellent) }\end{array}$ & 18.8 & - & 1035 & 10.5 & - & 76 & 8.1 & - & 74 \\
\hline Chronic conditions $* * *$ & 1.2 & 1.0 & 1186 & 1.3 & 1.0 & 79 & 1.9 & 1.3 & 81 \\
\hline
\end{tabular}

${ }^{*} p \leqslant 0.05 ;{ }^{* *} p \leqslant 0.01 ; * * * p \leqslant 0.001$.

noteworthy. Consistent trends across the three groups in peak expiratory flow were observed, with those in the high functioning groups performing at the highest levels $(p \leqslant 0.001)$. The second significant association is between DHEAS and functional status, with those in the high functioning group having the highest levels $(p \leqslant 0.001)$. Among the remaining physiologic parameters only waist-hip ratio shows a trend $(p \leqslant 0.05)$ with increasing ratios of waist to hip circumference associated with membership in poorer functioning groups.

The data on productivity and other psycho- social conditions presented in Table 6 indicate those subjects in the high functioning group are doing well in other domains of functioning, particularly those involving psychological well-being and productive activities. They are much more likely to engage in volunteer activities than those in the medium and low groups (22 hours/year vs 6 or 5 hours/year) $(p \leqslant 0.01)$. Furthermore, they are significantly more likely to score higher on scales of self-efficacy, personal mastery, life satisfaction and report fewer psychiatric symptoms $(p \leqslant 0.01)$.

Table 5. Biomedical and neuroendocrine values in high, medium and low functioning groups

\begin{tabular}{|c|c|c|c|c|c|c|c|c|c|}
\hline \multirow[b]{2}{*}{ Condition } & \multicolumn{3}{|c|}{ High } & \multicolumn{3}{|c|}{ Medium } & \multicolumn{3}{|c|}{ Low } \\
\hline & $\bar{x}$ & SD & $n$ & $\bar{x}$ & SD & $n$ & $\boldsymbol{X}$ & SD & $n$ \\
\hline $\begin{array}{l}\text { Plmnry. funct.*** } \\
\text { peak expiratory } \\
\text { flow (l/min) } \\
\text { DHEA-S }\end{array}$ & 356 & 119 & 1180 & 304 & 126 & 78 & 280 & 123 & 80 \\
\hline $\begin{array}{l}\text { (mg/dl)**** } \\
\text { Uri Cortisol }\end{array}$ & 69 & 49 & 942 & 57 & 51 & 62 & 48 & 40 & 58 \\
\hline (mg/g creat) & 25 & 23 & 995 & 23 & 36 & 65 & 22 & 19 & 64 \\
\hline $\begin{array}{l}\text { Uri norepinephrine } \\
\text { (mg/g creat) } \\
\text { Uri epinephrine }\end{array}$ & 47 & 47 & 998 & 48 & 81 & 65 & 38 & 21 & 62 \\
\hline (mg/g creat) & 4.4 & 3.9 & 1010 & 4.5 & 2.8 & 65 & 4.3 & 2.2 & 62 \\
\hline $\begin{array}{l}\text { Uri dopamine } \\
\text { (mg/g creat) } \\
\text { Total serum }\end{array}$ & $\begin{array}{l}293 \\
220\end{array}$ & $\begin{array}{r}266 \\
42\end{array}$ & $\begin{array}{r}1006 \\
952\end{array}$ & $\begin{array}{l}264 \\
215\end{array}$ & $\begin{array}{r}112 \\
45\end{array}$ & $\begin{array}{l}65 \\
64\end{array}$ & $\begin{array}{l}261 \\
208\end{array}$ & $\begin{array}{r}115 \\
43\end{array}$ & $\begin{array}{l}62 \\
64\end{array}$ \\
\hline Chol (mg/dl) & & & & & & & & & \\
\hline HDL chol (mg/dl) & 48 & 15 & 951 & 48 & 19 & 64 & 43 & 14 & 64 \\
\hline hemoglobin $(\%)$ & 6.8 & 1.9 & 945 & 7.2 & 2.1 & 61 & 7.3 & 1.6 & 57 \\
\hline SGOT (v/1) & $\begin{array}{l}18 \\
0.91\end{array}$ & 12 & $\begin{array}{r}945 \\
1188\end{array}$ & $\begin{array}{l}19 \\
0.92\end{array}$ & 9 & $\begin{array}{l}64 \\
79\end{array}$ & 9 & $\begin{array}{l}11 \\
0.07\end{array}$ & $\begin{array}{l}64 \\
75\end{array}$ \\
\hline Obesity (BMI) & 25.9 & 4.2 & 1071 & 26.6 & 4.8 & 68 & 26.6 & 5.5 & 67 \\
\hline $\begin{array}{l}\text { BP_-Diastolic } \\
\text { BP-Systolic }\end{array}$ & $\begin{array}{r}77 \\
138\end{array}$ & $\begin{array}{l}10 \\
19\end{array}$ & $\begin{array}{l}1183 \\
1183\end{array}$ & $\begin{array}{r}81 \\
141\end{array}$ & $\begin{array}{l}13 \\
20\end{array}$ & $\begin{array}{l}80 \\
80\end{array}$ & $\begin{array}{r}77 \\
136\end{array}$ & $\begin{array}{l}12 \\
20\end{array}$ & $\begin{array}{l}81 \\
81\end{array}$ \\
\hline
\end{tabular}

* $p \leqslant 0.05 ;{ }^{* *} p \leqslant 0.01 ;{ }^{* * *} p \leqslant 0.001$. 
Table 6. Psychosocial factors in high, medium and low functioning groups

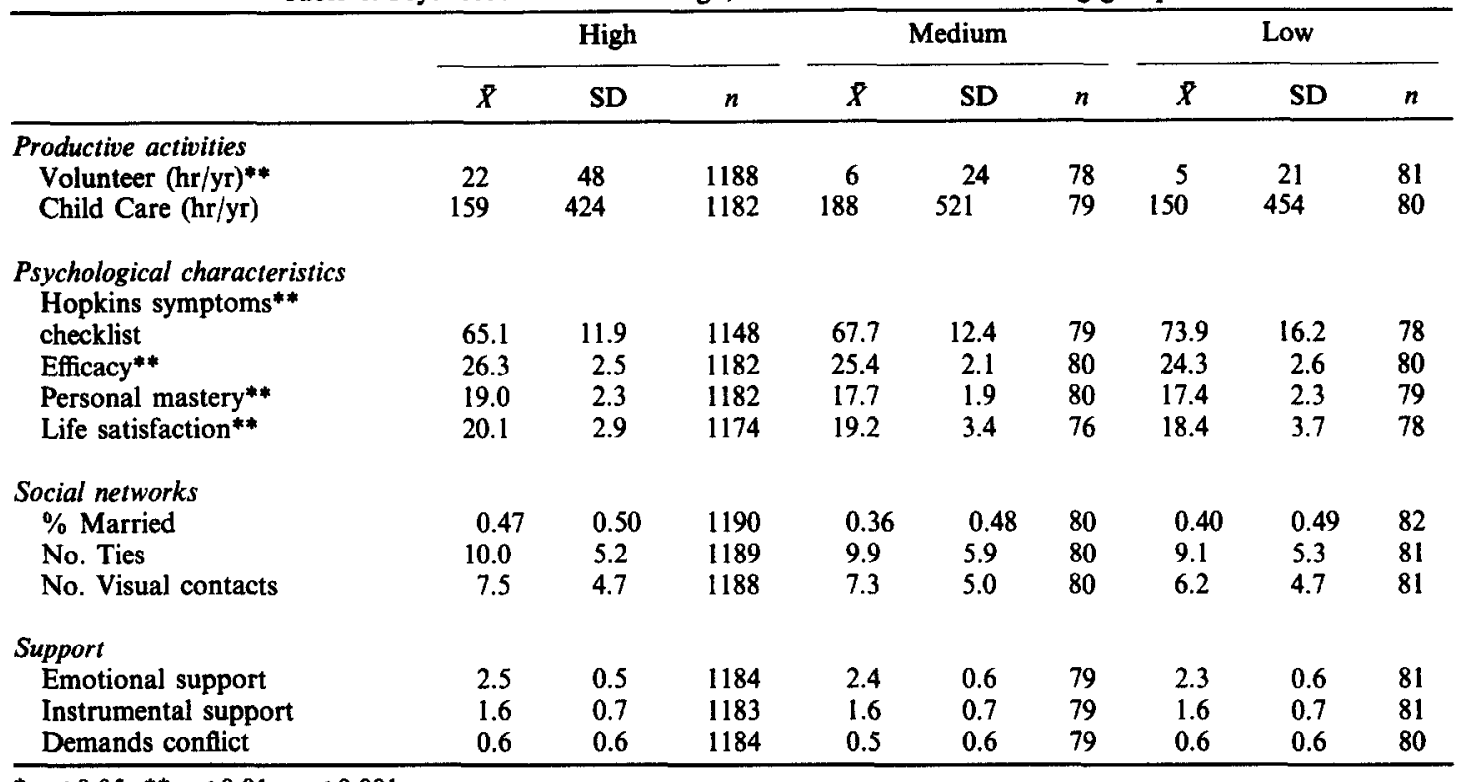

${ }^{*} p \leqslant 0.05 ;{ }^{* *} p \leqslant 0.01 ; p \leqslant 0.001$.

\section{DISCUSSION}

Preoccupation with serious impairments and disabilities in epidemiologic research in gerontology has led to the development of measures of physical and cognitive function that identify the small population with such impairments but has done little to describe the abilities of $85-90 \%$ of the population free of such disability. We sought to develop appropriate measures of physical and cognitive functioning that would describe the heterogeneity we suspected was evident in elderly populations. Virtually all the performance-based measures of physical and cognitive ability discriminated those in the highest group from those in the two lower functioning groups. The variance in the scores in the highest functioning group indicates still greater heterogeneity in this already high functioning group. Thus, based on this initial wave of interviews and examinations, we have found that it is possible to develop simple well-received home-based measures of physical and cognitive function that will array people along a wide spectrum of abilities.

\section{Success across domains of experience}

Operationalization of the concept of high functioning or what is sometimes referred to as successful aging is difficult. We suspect that every individual harbors a somewhat unique and idiosyncratic view of the scope of such a definition and essential abilities. Some view "successful aging" as primarily a psychological phenomenon having to do with adaptation [39] and mastery; others see it as the fulfillment of certain social roles and productive activities. Still others view it as the avoidance of specific diseases or as exceptional performance in one domain of function or another. In our study, we have focused on the joint physical and cognitive abilities of older men and women. Our reasoning is that with the loss of any of these functional abilities, serious compromises and withdrawal from independence and social interaction are likely.

We recognize that there are certain limitations inherent in defining a group of "high functioning" older men and women on the basis of their levels of performance on both physical and cognitive criteria. For instance, people who have had life-long disabilities, especially those related to mobility, may not meet criteria in spite of obvious potential for what most would consider "successful aging". Furthermore, by selecting the top tertile of functioning on the basis of both criteria, some subjects will inevitably fall in the range of more average or "normal" abilities on any single criteria. It is important to note however that individuals selected on the basis of these brief assessments of physical and cognitive function were also found to perform much better than those in the middle and lower groups on a wide array of more complex and difficult performance-based measures of cognitive and physical ability. 
Most importantly and by far the most remarkable finding of our study is that people who are high functioning also performed better on a more diverse set of assessments of psychosocial and physiological functioning. For instance, they were found to have greater pulmonary function, based on peak expiratory flow, and their self-rated health was much better. In the social and behavioral areas, they were much more likely to engage in productive activities and strenuous physical exercise. In the domain of psychological well-being, they reported greater feelings of self-efficacy, mastery, and life satisfaction. They were less likely to report feelings of anxiety and depression than others. These latter assessments of social and psychological characteristics were in no way part of the screening instrument. Thus, older people who are identified from a brief screening instrument for functional status are also doing well across a number of other domains.

A second limitation of this study is that it is cross-sectional and it is therefore difficult to interpret the direction of effects. Particularly problematic areas are the extent to which (1) disease per se influence performance levels and psychological and social status; (2) behaviors such as physical activity and psychological states such as depression or self-efficacy are reflections of functional states or consequences of them. These issues will need to be resolved in future longitudinal analyses which are planned. More generally, most definitions of successful aging, including ours, rely heavily on concepts involving the dynamics of change and the maintenance of abilities under situations of stress or challenge. It is only by undertaking longitudinal analyses that such patterns and processes are identifiable.

\section{The correlates of high functioning}

Several studies have examined predictors of high functioning. In Framingham, Pinsky and co-investigators [40] identified very few cardiovascular risk factors predictive of good functioning. Among men, alcohol consumption, cigarette smoking, ventricular rate and education were significant predictors. For women, only education was related to functioning. Physiologic parameters that did not predict included serum cholesterol, hematocrit, serum glucose, blood pressure, body mass and vital capacity. The failure of these traditional and important risk factors for morbidity and mortality to predict functioning indicates that the predictors of functional ability may be substantially different from those for morbidity and mortality. On the other hand, in studies of older people in Alameda County [41] and very old subjects in the N-HIS [42], prevalent cardiovascular disease and history of hypertension predicted declines in function. In both these studies, selected indicators of socioeconomic status predicted functional ability. In the Manitoba study [43] in which multiple indicators of socioeconomic status were assessed, only selected chronic conditions, self-rated health, and loss of a spouse predicted successful aging as defined in terms of functional ability.

Since our findings are cross-sectional, it is not surprising that such indicators as self-rated health are related to functional status. However, our findings parallel those from Framingham in that few risk factors for cardiovascular disease, with the exception of cigarette smoking, are associated with functioning. Serum cholesterol, glycosylated hemoglobin, body mass, and blood pressure did not vary across the groups. However, we have found that several factors not previously studied in this context are related to functional status. In this study, DHEAS was found to vary significantly across the three functioning groups with higher values found in the highest functioning group. Previous studies have reported DHEAS to be associated with mortality risk [44]; however, to our knowledge, no one has yet found an association between DHEAS and functional level. A second finding of importance is the relationship between pulmonary function and physical and cognitive functioning. Again, such assessments have been reported to predict increased mortality risk in older men and women [32] but had not been examined in relation to functional status. In studies of exercise capacity however, pulmonary function is related to levels of cardiovascular fitness and performance.

\section{The importance of socioeconomic conditions}

By far the most consistent finding to date, and one of our major findings is the association of poverty and lower levels of education with poor functioning. Studies from Framingham, Alameda County, and N-HIS report similar findings. Studies of cognitive ability consistently reveal educational differentials in performance [45-47]. The reasons for such an association are likely to be multiple but have so far been poorly articulated and understood. They range from those vulnerable populations with limited 
economic resources having poorer access to healthcare and more medically uncontrolled chronic conditions to differences in patterns of life-long health-related behaviours and limited other psychological or social resources [48]. Current differences in functional levels may reflect recent changes, life-long patterns or even exposures or nutritional patterns of earlier life stages. We regard the assessment of the role that socioeconomic and other related psychosocial conditions play in influencing change in functioning over time as one of the most important components of this research.

Acknowledgements-This work was supported by the MacArthur Foundation Research Network on Successful Aging. It was approved by appropriate institutional review boards at Yale, Massachusetts General Hospital and Duke University. The authors wish to thank Michael Nevitt, Mary Tinetti, Loretta DiPietro and Jack Guralnik for help in the development of several of the measures we used in this study.

\section{REFERENCES}

1. Rowe JW, Kahn RL. Human aging: usual and successful. Science 1987; 237: 143-149.

2. Fries JF. The sunny side of aging. JAMA 1990; 263.

3. Cornoni-Huntley J, Brock DB, Ostfeld AM, Taylor JO, Wallace RB. 1986 established populations for the epidemiologic studies of the elderly: resource data book. NIH Publication No. 86-2443. NIH, Bethesda, MD.

4. Pfeiffer E. A short portable mental status questionnaire for the assessment of organic brain deficit in elderly patients. J Am Geriatr Soc 1975; 23: 433-441.

5. Katz S, Downs TD, Cash HR et al. Progress in the development of an index of ADL. Gerontologist 1970; 10: 20-30.

6. Nagi SZ. An epidemiology of disability among adults in the United States. Milbank Q 1976; 54: 439-468.

7. Rosow I, Breslau N. A Guttman health scale for the aged. J Gerontol 1966; 21: 556-559.

8. Kaplan E, Goodglass H, Weintraub S. Boston Naming Test. Philadelphia, PA: Lea \& Febiger; 1983.

9. Welsh K, Butters N, Hughes J, Mohs R, Heyman A. Detection of abnormal memory decline in mild cases of Alzheimer's disease using CERAD neuropsychological measures. Arch Neurol 1991; 48: 278-281.

10. Morris JC, Heymann A, Mohs R, Hughes JP, Van Belle G, Fillenbaum G, Mellits ED, Clark C, and the CERAD investigators. The consortium to establish a registry for Alzheimer's Disease (CERAD). Part I. Clinical and neuropsychological assessment of Alzheimer's disease. Neurology 1989; 39: 1159-1165.

11. Moss M, Albert M, Butters N, Payne M. Differential patterns of memory loss among patients with Alzheimer's disease, Huntington's disease, alcoholic Korsakoff's syndrome. Arch Neurol 1986; 43: 239-246.

12. Wechsler D. Adult Intelligence Scale-Revised. New York: Psychological Corporation; 1981.

13. Rosen W, Mohs R, Davis R. A new rating scale for Alzheimer's disease. Am J Psychiatry 1984; 141: 1356-1364.

14. Tinetti MF, Williams FT, Mayewski R. A fall risk index for elderly patients based on number of chronic disabilities. Am J Med 1986; 80: 429-434.
15. Nevitt MC, Cummings SR, Kidd S, Black D. Risk factors for recurrent nonsyncopal falls. JAMA 1989; 261: 2663-2668.

16. Williams ME, Hadler NM, Earp JL. Manual ability as a marker of dependency in geriatric women. J Chron Dis 1982; 35: 115-122.

17. DiPietro L, Caspersen CJ, Ostfeld AM, Nadel ER. A survey for assessing physical activity among older adults. Med Sel Sports Exerc 1993; 25: 628-642.

18. Paffenbarger RS, Wing AL, Hyde RT. Physical activity as an index of heart attack risk in college alumni. Am J Epidemiol 1978; 108: 161-175.

19. Taylor HL, Jacobs DR, Schucker J et al. A questionnaire for the assessment of leisure-time physical activity. J Chron Dis 1978; 31: 741-755.

20. Herzog AR, Kahn RL, Morgan JN, Jackson JS, Antonucci TC. Age differences in productive activities. J Gerontol 1989; 44: 129-138.

21. Seeman T, Berkman LF. Characteristics of social networks and the provision of social support in the elderly: who provides support? Soc Sci Med 1988; 26: 737-749.

22. House JS. Americans' Changing Lives: Wave I, 1986 (computer file). Ann Arbor, MI: Survey Research Center (producer); 1989. Ann Arbor, MI: Inter-University Consortium for Political and Social Research (distributor); 1990.

23. Landerman R, George LK, Campbell RT, Blazer DG. Alternative models of the stress buffering hypothesis. Am J Commun Psychol 1989; 17: 625-642.

24. Derogatis LR, Lipman RS, Rickels K, Uhlenhuth EH, Covi L. The Hopkins Symptom Checklist (HSCL): a measure of primary symptom dimensions, In: Pichot, P, Ed. Psychological Measurement: Modern Problems in Pharmacntherapy. Basel: S. Karger; 1973.

25. Derogatis LR, Lipman RS, Rickels K, Uhlenhuth EH, Covi L. The Hopkins Sympton Checklist (HSCL): a self-report symptom inventory. Behav Sei 1974; 19 1-15.

26. Pearlin LI, Schooler C. The structure of coping. J Health Soc Behav 1978; 18: 2-21.

27. Rodin J, McAvay. Determinants of change in perceived health in a longitudinal study of older adults. J Gerontol 1993; 47: P373-P384.

28. Campbell A, Converse PE, Rogers WL. The Quality of American Life. New York: Russell Sage; 1976.

29. Karasek R, Theorell T. Healthy Work: Stress, Productivity, and the Reconstruction of Working Life. New York: Basic Books; 1990.

30. HDFP-Hypertension Dection, and Follow-up Program Cooperative Group. Variability of blood pressure and results of screening in HDFP program. J Chron Dis 1978; 31: 651-667.

31. Lohmen TG, Roche AF, Martorell R. Anthropometric Standardization Reference Manual. Champaign, IL: Human Kinetics Books; 1988.

32. Cook NR, Evans DA, Scherr PA, Speizer FE, Taylor JO, Hennekens $\mathrm{CH}$. Peak expiratory flow rate and 5-year mortality in an elderly population. Am J Epidemiol 1991; 133: 784-794.

33. Rose GA, Blackburn H, Gillium RF, Prineas RJ Cardiovascular Survey Methods. Geneva: World Health Organization; 1982: 162-165.

34. Caldrella A, Reardon G, Canalis E. Analysis of cortisol in serum by liquid chromatography. Clin Chem 1982; 28: 538-543.

35. Canalis E, Reardon G, Caldrella A. A more specific, liquid chromatography for free cortisol in urine. Clin Chem 1982; 28: 2418-2420.

36. Krsulovic AM. Investigations of catecholamine metabolism using high performance liquid chromatography: 
analytical methodology and clinical applicators. J Chromatogr 1983; 9: 1-34.

37. Little RR et al. Effects of whole blood storage on results of glycosolated hemoglobin as measured by ion exchange chromatography, affinity chromatography and colorimetry. Clin Chem 1983; 29: 1080-1082.

38. SAS Institute Inc. The GLM Procedure. In: SAS User's Guide: Statistics 5th edn. Cary, NC: SAS Institute; 1985: 434-506.

39. Butt DS, Beiser $M$. Successful aging: a theme for international psychology. Psychol Aging 1987; 2: 87-94.

40. Pinsky JL, Leaverton PE, Stokes III J. Predictors of good function: the Framingham study. J Chron Dis 1987; 40: 1595-1675.

41. Guralnik JM, Kaplan GA. Predictors of healthy aging: prospective evidence from the Alameda County Study. Am J Public Health 1989; 79: 703-708.

42. Harris $T$, Kovar MG, Suzman R, Kleinman JC, Feldman JJ. Longitudinal study of physical ability in the oldest-old. Am J Public Health 1989; 79: 698-702.

43. Roos NP, Havens B. Predictors of successful aging: a twelve-year study of Manitoba elderly. Am J Public Health 1991; 81: 63-69.

44. Barrett-Connor E, Yen SSC. A prospective study of dehydroepiandrosterone sulfate, mortality, and cardiovascular disease. N Engl J Med 1986; 315: 1519-1524.

45. Evans DA, Funkenstein H, Albert MS, Scherr PA, Cook NR, Chown MJ, Herbert LE, Hennekens Ch, Taylor JO. Prevalence of Alzheimer's disease in a community population of older persons. JAMA 1989; 262: 2551-2556.

46. Fillenbaum GG, Hughes DC, Heyman A, George LK, Blazer DG. Relationship of health and demographic characteristics to Mini-Mental State Examination score among community residents. Psychol Med 1988; 18: 719-726.

47. Brayne C, Callowsay $P$. The association of education and socioeconomic status with Mini Mental State Examination and the clinical diagnosis of dementia in elderly people. Age and Ageing 1990; 19: 91-96.

48. Berkman LF. The association between educational attainment and mental status examinations of etiological significance for senile dementias or not? J Chron Dis 1986; 39: 171-174. 